\title{
A TONTAS Y A LOCAS. EXIGENCIAS DE UN SURREALISMO TOUT-AUTRE ${ }^{1}$
}

\author{
Federico RODRÍGUEZ GÓMEZ \\ Universidad de Sevilla \\ frogo@us.es
}

A mi dálmata, Nadja, si loin.

Il faut lui rendre justice. Il m'a beaucoup crétinisé (Isidore Ducasse, Les Chants de Maldoror, 1869).

Je souffre d'une effroyable maladie de l'esprit. Ma pensée m'abandonne, à tous les degrés [...]. Il y à donc un quelque chose qui détruit ma pensée [...] qui détruit au fur et à mesure dans sa substance la masse de ma pensée [...] je ne demande plus qu'à sentir mon cerveau (Antonin Artaud, Correspondance avec Jacques Rivière, 1927).

$\mathrm{O}$ ui, j'ai des confidences à vous faire sur le comte impensable de Lautréamont» (Artaud, 2004: 1250, bastardilla nuestra). Así comienza la carta que «el pobre señor A. Artaud» escribe a petición de Jean Ballard para el ejemplar 275 de la

\footnotetext{
${ }^{1}$ Este texto es de alguna manera la segunda parte de «Death sentences: wie man wird, was man ist. Empedrando la bêtise en J. D.» (Escritura e imagen, vol. extra, 2011: Herencias de Derrida / Héritages de Derrida, 2011; en prensa). Si allí, partiendo de los límites y legitimaciones de la filosofía como antropología filosófica (estudios postkantianos: qué es el Hombre - Ecce homo), privilegiábamos sobre todo la lectura que Derrida realizaba de G. Flaubert y de Ch. Baudelaire, ahora nos desplazamos hacia la que lleva a cabo de I. Ducasse, Conde de Lautréamont. Ni se trataba entonces ni se trata ahora de ser exhaustivos con estas lecturas, con la multiplicidad de dispositivos que las habitan; tampoco de ver qué escribe Derrida sobre una serie de autores considerados del lado de lo literario (de una idiomaticidad francófona); no es eso lo que nos interesaba entonces, tampoco ahora. El objetivo es más bien sacar a flote una configuración: la que lleva a cabo Derrida de la bêtise decimonónica francesa, y su repercusión, vía SA (Savoir Absolu), en lo que puede querer-decir poder-pensar hoy. No obstante, esta vez, el desplazamiento que realizaremos en el epígrafe segundo hacia Artaud, el loco, y hacia la palabra impouvoir, desplazamiento al que parece llevar toda bêtise y todo «efecto de cretinización», todo devenirpiedra y sin-mundo, servirá de complemento para lo que sólo vamos a comenzar aquí a dibujar: un surrealismo tout-autre, a tontas y a locas, en las filiaciones entre la historiografía clásica sobre el surrealismo, el psicoanálisis y la deconstrucción.
} 
revista Cahiers $d u$ Sud, dedicado al malvado Isidore Ducasse, Conde de Lautréamont, en 1946. No parecía un mal motivo para comenzar también un texto escrito para un volumen dedicado a Jacques Derrida y «la literatura». Aquí se tratará también del murmullo de algunas confidencias más o menos secretas -«on hérite toujours un secret - qui dit "lisez moi, en serais-tu jamais capable?"» (Derrida, 1995: 40)-; tratar de dar pequeños fogonazos en medio de un océano de signos. Pero no para ilustrar («Illustrer, dit-il») y volver a heredar la pregunta antropológica fundamental (Qué es el hombre / Qué es la Ilustración: memorias de la gran Época de la Crítica), sino sólo para volver a dejarlo todo un poco a la sombra, deforme, entre el polvo y los muertos, en silencio. Unas pocas confidencias pues, sí, pero no tanto (a) sobre el impensable Conde de Lautréamont -Artaud se refiere en su carta dos veces a este carácter impensable del hombre, de la obra o de la vida del poeta-, tampoco particularmente (b) sobre el impensable Artaud, que sabemos que ya, desde los años de la correspondencia con Jacques Rivière, no podía pensar más -«ma pensée m'abandonne, à tous les degrés» (Artaud, 2004: 69)-, sino más bien (c) sobre el no menos impensable Jacques Derrida, que tanto ha pensando a Artaud, que tanto ha pensado sobre la imposibilidad misma de Artaud, y que también se habrá referido a una cierta imposibilidad de pensar a Lautréamont. De este modo, se trataría de ver cómo se dividen Lautréamont y Artaud, partage amoureux, en Derrida; $y$, antes bien, lo que estos mismos ponen en juego en sus literaturas en relación con lo que pensar puede o no querer-decir hoy -no sólo pensar un nombre propio, una firma o una obra, sino llegar a pensar, poder pensar, en general; no se trata por tanto simplemente de casos particulares; y esto, como señalará Deleuze, ya lo vio el propio Artaud, para quien la cuestión del pensar fue uno de los grandes, sino el más grande, problema ${ }^{2}$; se trata pues de un «proceso generalizado» ( $c f$. Deleuze, 2005: 191)-, y con la manera que Derrida ha tenido de leer estos gestos escriturales entre literatura y filosofía ${ }^{3}$. A riesgo de no atinar, esta puesta en juego de algunos caracteres de sus escrituras -insistimos: por un lado, (a) desde la labor de una cierta confidenciahistórica, archivista, profanamente lumínica -«profane Erleuchtung» ( $c f$. Benjamin, 1975: 298)-, y, por otro, (b) desde la caracterización filosófica de lo impensable-, lo vamos a enmarcar dentro de lo que llamaremos un «surrealismo tout-autre» ${ }^{4}$. Es quizá preciso recordar que no otra cosa, sino el pensamiento, es lo que ha estado siempre

\footnotetext{
${ }^{2}$ Escribe Ph. Sollers: «Dans tous ces écrits, du début à la fin de la trajectoire de rayée de sa vie, il n'est pas de mot qu'Artaud prononce plus souvent, ni avec plus d'obstination et de force que celui de pensée [...] La pensée est précisément ce qui commence à être refusé à Artaud» (Sollers, 1968: 88, 90; bastardilla nuestra).

${ }^{3}$ Particularmente en sus primeros escritos, desde 1965 hasta 1971, en el momento de las conjunciones y diferencias con Tel Quel, momento en donde se conjura un cierto dispositivo de lectura, su gran telaraña, repleta de trampas y túneles subterráneos, a partir de una atmósfera muy específica.

${ }^{4}$ Porque el objetivo primero del surrealismo, es preciso recordarlo, objetivo que está incluido en la propia definición que del mismo se encuentra en el primer manifiesto de 1924 es: «on se propose d'exprimer [...] le fonctionnement réel de la pensée» (Breton, 1972: 328; bastardilla nuestra).
} 
primordialmente en juego con el surrealismo; pero ¿qué pensamiento? Paule Thévenin, íntima de Derrida en los sesenta desde la publicación en 1965 de «La parole soufflée» ( $c f$. Peeters, 2010: 197-199), y autora a la que éste dedicará, en señal de reconocimiento y amistad, tanto su segundo artículo sobre Artaud («Le théâtre de la cruauté et la clôture de la représentation», 1966) como su último librito, realizado sobre la exposición de sus dibujos en el Moma de New York ( $c f$. Derrida, 2002a) ${ }^{5}$, reivindicó ya otro surrealismo, un surrealismo diferente ( $c f$. Thévenin, 2006), específicamente un «surrealismo en la diferencia», siguiendo quizá a su modo, como sugiere Michel Surya en el prefacio a la obra, el «gran surrealismo» exigido por otro surrealista excomulgado como G. Bataille y leyendo para ello y «par cœur» la obra del prácticamente desconocido en esos años A. Artaud -quien habría escrito, a propósito precisamente de confidencias y de secretos, será preciso igualmente tenerlo presente para todo esto, que «le secret du Surréalisme est qu'il attaque les choses dans leur secret» (Artaud, 2004: 687); secreción, excreción si se quiere, del secreto («ça sécrète»; Derrida, 1974: 263b)-.

Ciertamente, hay varias historias del surrealismo al margen de la que se escribe fundamentalmente bajo el báculo de diamantes del gran druida, A. Breton. Y, de la misma manera que se puede hablar (a) de Lautréamont como precursor del surrealismo -una «escritura-automática» avant la lettre-, de Ducasse como semilla o bálsamo nutricio (vía Ph. Soupault y L. Aragon), dentro de una lógica cuasi-hegeliana de desarrollo y florecimiento, o, del mismo modo que alguien podría igualmente interesarse (b) por Artaud como detritus o mierda del surrealismo ${ }^{6}$, alguien podría también interesarse ${ }^{7}$ por (c) «los surrealismos», por la post-surrealidad, por seguir hablando narrativamente y desde una cómoda ficción-historicista, de Derrida; interesarse por la manera que éste tiene de heredar temas, gestos o nombres surrealistas; hacerlo pese a que, en principio, las alusiones al surrealismo como tal sean escasas a lo largo de sus escritos - probablemente el paso por Tel Quel a mediados de los sesenta y la atmósfera anti-surrealista que allí se respiraba tengan algo que ver-; imaginar pues algún tipo de acoplamiento entre lo posible -lo real, la conciencia, el cálculo- y lo

\footnotetext{
${ }^{5}$ Como se recordará, ya «Forcener le subjetile» (Derrida, 1986), lo mejor que se había escrito en lengua francesa sobre Artaud hasta entonces a juicio de G. Deleuze, aparece en un volumen conjunto editado por ambos.

${ }^{6}$ Inasimilable, surrealista a su modo, surrealista antes que todo surrealista y de una manera diferente, no cronológica, a Lautréamont; «Artaud est le surréalisme que les surréalistes ont désavoué» (Nin, 1970: 271); el libro póstumo de $P$. Thévenin al que nos hemos referido (escrito en los años setenta) es una de las mejores manifestaciones; Derrida, por su parte, recoge este pasaje entre el surrealismo y Artaud en una nota de «La parole soufflée» ( $c f$. Derrida, 1967: 283-284). Para las cuestiones entre Artaud y el surrealismo en el horizonte del problema de la revolución (cf. Artaud, 2004: 236-246, 686-692; Bonnet, ed., 1992; Mèredieu, 2006: 311-336; y el cortometraje O proceso de Artaud: Ledo: 2010).

${ }^{7}$ Como lo ha hecho ya, de otro modo, Jean-Michel Heimonet en su libro Politiques de l'écriture, Bataille / Derrida. Le Sens du sacré dans la pensée française du surréalisme à nos jours (cf. Heimonet, 1990), o, J. Brannigan en su artículo «We have nothing to with Literature. Derrida and Surrealist Writing» ( $c f$. Branningan, 1999: 53-70).
} 
imposible -el sueño, el inconsciente, la sorpresa- en las afinidades y diferencias entre «surrealismo»y «deconstrucción». La pista, para los que como nosotros sean buenos amigos de la ancestral raza de los sabuesos, siempre puede seguirse ejemplarmente desde el tratamiento que Derrida hace de la cuestión onírica, corazón del surrealismo; o dicho de otro modo: desde las herencias de la Traumdeutung ${ }^{8}$ que se establecen al menos desde $1966^{9}$ y hasta las lecturas de W. Benjamin en Fichus. Discours de Francfort en 2001. Pero aquí dejaremos de lado lo onírico y la cuestión de la composición de la/s lengua/s del sueño -Freud, el carácter contradictorios de las lenguas antiguas, la ejemplaridad de la lengua egipcia, los jeroglíficos (bajo los que se escribe asimismo la figura de Artaud), los secretos de la esfinge, lo siniestro, etc.-; también dejaremos de lado ese vuelco que provocó el surrealismo en las maneras expositivas de la filosofía ${ }^{10}$-la prosa, la forma, el estilo, la exposición, el método, la realización: la génesis misma de la lengua y del sentido, los problemas genéticos de una imaginación que, dijo Breton, y era lo que más amaba de ella, no perdonaba, etc.-, maneras que pueden leerse también en Derrida; e, igualmente, dejaremos de lado un mismo gusto por los fetiches (el falo, la boca, los pechos, etc.), más allá de la sublimación idealizante de las cosas mismas, o por los acontecimientos (événements) y la improvisación más allá del orden de posibles calculados, más allá de lo esperado, es decir, de un cierto modo de entender la soberanía -y aquí la lectura que Derrida realiza igualmente de Bataille en 1966, «De l'économie restreinte à l'économie générale. Un hégélianisme sans réserve»

\footnotetext{
${ }^{8}$ G. Michaud ha escrito varias páginas admirables sobre los sueños en Derrida/Cixous en «Comme en rêve... Lire Jacques Derrida avec H. Cixous» (cf. Michaud, 2010). Por nuestra parte, hemos desarrollado algunos aspectos de este problema onírico desde las imbricaciones entre psicoanálisis y deconstrucción en: «Palimpsestos onirocríticos. Hacia una psico-grafía de lo siniestro» (Thémata. Revista de filosofía, 45 , 2012, pp. 359-382).

${ }^{9}$ Con, particularmente, «Freud et la scène de l'écriture», texto que, no hay que olvidarlo, se publica por primera vez en Tel Quel, y en los años de la resurrección por parte de la revista de Artaud y Bataille como detritus surrealistas, mediante lo que era, manifiestamente, un distanciamiento activo frente al surrealismo de Breton y cía. (un Breton que, precisamente, no abandonará nunca a Hegel, lo que Hegel pensará sobre el pensamiento; dirá en 1952 en Entretiens «où la dialectique hégélienne ne fonctionne pas, il n’y a pas pour moi de pensée, pas d'espoir de vérité» [Breton, 1973: 154; bastardilla nuestra]; se comprenderá que se trata, con estos otros movimientos, de ver qué pensamiento es posible más allá de la dialéctica hegeliana, a la que Breton engalana ya desde el primer manifiesto asegurando que siempre se ha de acudir a Hegel para ver si la actividad surrealista está o no adecuadamente fundada; dicho de otro modo: hacer que sea $S A$, quien o el que, sécrète; desangramiento interno e indefinido del saber; Deleuze y Derrida, Bataille mediante, no han dejado de mostrarlo de maneras bien diferentes) y como crítica furibunda, insistamos en ello, a todo lo que podía enmarcarse entonces bajo el rótulo de neo-surrealismo: «À bas le surréalisme! Vive l'avant-garde!» ( $c f$. Forest, 1995: 436 y ss.).

${ }^{10}$ Como es sabido, la obra de W. Benjamin, y en especial los Passagen-Werke, ha sido sin duda el caso ejemplar de una increíble «filosofía surrealista»: choque heterogéneo de materiales (la máquina de coser y el paraguas sobre la mesa de disección del malvado Conde), collage, duelo, revolución interminable de la historia, tarea de los traductores, etc. Ya «Der Sürrealismus. Die letzte Momentaufnahme der europäischen Intelligenz», un texto de 1929, ofrece los elementos de esta maquinación. Adorno ha dado cuenta de ello, en algunas malévolas introducciones a su pensamiento, al decir, por ejemplo, que la filosofía de Benjamin no debía simplemente recoger la herencia del surrealismo sino ser surrealista ella misma: «Philosophie sollte nicht bloß den Surrealismus einholen, sondern selber surrealistisch werden» (Adorno, 1974: 250).
} 
(cf. Derrida, 1967: 373-384), resulta igualmente determinante-. Lo haremos convencidos de que no se trata de succionar de dos ubres distintas de la fértil vaca -«la mère nourricière» (Derrida, 2002b: 33)- psicoanalítica, la del «surrealismo» y la de «Tel Quel / deconstrucción», sino más bien de la lucha por succionar del mismo pezón, el más rico, el que conduce al ombligo del sueño (Nabel des Traums), en los contagios que se producen en la alternancia de las bocas sobre una misma fuente; lo haremos pues sólo para poder desplazarnos, con mayor eficacia y sin tener que cargar un fardo demasiado pesado para estas exigencias contextuales, hacia dos de los motivos, probablemente las dos grandes exigencias, de un surrealismo tout-autre: (1) la castración teleológica, lo

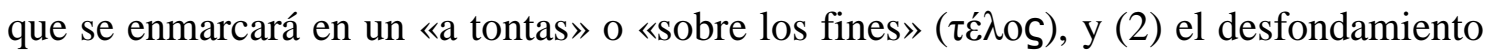
genético, lo que se trabajará con mayor brevedad dado que su tratamiento, más allá del comentario del mismo en Artaud, sobrepasaría igualmente los límites que se impone este texto, desde un «a locas»o «sobre los orígenes» ( $\gamma \varepsilon \dot{v} v \varsigma$ ). Quizá, quién sabe, sea una cierta surrealidad no asumible, nutritiva y fresca leche primigenia de la que se alimentarían los sueños y todos los excesos (Űßpıs), la que siga después de todo trabajando la posibilidad misma del pensamiento; y entonces probablemente haya algo todavía que hacer, tareas pendientes, entre esos dos grandes y pesados nombres que son, más allá de toda nominalidad propia, «deconstrucción» y «surrealismo»; hacerlo a la salud de la literatura, hacerlo aún y cuando el surrealismo exceda siempre toda literatura.

\section{$\S 1$. A tontas: para una cretinización del lector.}

Ce sentiment de remarquable stupéfaction, auquel on doit généralement chercher à soustraire ceux qui passent leur temps à lire des livres ou des brochures, j'ai fait tous mes efforts pour le produire. En effet, il m'était impossible de faire moins, malgré ma bonne volonté... (Isidore Ducasse, Les Chants de Maldoror, 1869).

Un día, un Derrida-scholar podría soltar, un poco mediante balbuceos y embarullamientos, a tontas y a locas, lo siguiente: «la escritura de Derrida, escritura, gimnástica activa del pensamiento que habría llevado a "la filosofía" a su límite haciendo aparecer en el límite, en su porosidad constitutiva -cuestión de fronteras, de los fines del hombre y del animal autobiográfico: los encuentros de Cerisy-, la horda de animales dispersos que pueden encontrarse por sus escritos -es decir: la escritura de Derrida como deconstrucción de la filosofía si ésta, desde Kant, se ha constituido como antropología trascendental ${ }^{11}$-, no puede dejar de producir pasivamente, de tejer en el

\footnotetext{
${ }^{11}$ Habría que reconsiderar seriamente todas las cuestiones sobre el Kant-escritor, sobre sus torpezas y resistencias, sobre su talento, y sobre la popularización de la filosofía abiertas por J.-L. Nancy en Logodaedalus, 1975. A la oscura-luminosidad de la animalidad, se trataría de ver por qué el post-
} 
inconsciente más profundo de sus lectores, sino lo que llamaremos, siguiendo la brecha abierta por ciertos gestos decimonónicos clásicos, una 'cretinización fundamental'». Por supuesto, este alguien -cuestión de sujeto, de qui, de su eco: L'Écho du sujet, $\mathrm{Ph}$. Lacoue-Labarthe, etc.; del sujeto en proceso, work in progress de la subjetividad, sujetos larvarios, embriones, huevos (particularmente: G. Deleuze y todo lo relativo a «la verdad de la embriología»; pero también G. Simondon y el problema general de la «individuación»)-, este supuesto Derrida-scholar, no debería resultar completamente localizable.

Y en efecto: los textos de Derrida cretinizan; lo hacen para muchos, aunque a veces falte la palabra exacta, y aunque no haya sido hasta bien tarde cuando se haya visto una tematización expresa del problema -de manera insistente en el vol. I de $L a$ bête et le souverain: porque no hay que olvidar que crétiniser es abêtir, que la crétinisation es (como puede leerse en el Robert) un abêtissement; es decir, que el movimiento es «el mismo»: el de devenir menos inteligente de lo que se cree ser (la bêtise, su proceso, cuesta abajo y sin ruedas, pertenece a la esencia de la déchéance, dirá J. L. Nancy), el de pasar a colocarse del lado de las bestias (bêtes)-. Sí, si nos descuidamos y nos hacemos un poco el muerto dejándonos llevar por las olas-prosa, «J. D.» cretiniza. Logra cretinizar. Y lo consigue incluso, diríamos que sobre todo, en aquellos mercenarios que se adentran en su textos con puñales y lanzas de combate: para ellos están preparadas, especialmente, todas las neurosis imaginables. Lo hace más que nunca en casos-límite como, muy particularmente, y sobre todo cuando se trata de un «primer acceso», en las publicaciones que se realizan entre 1974 y 1980: Glas (1974), «+R» (1975), «Cartouches» (1976) y «Envois» (1979) serían quizá, junto con Circonfession (1989), uno de cuyos cuatro tiempos, como se recordará, viene de un diario de 1977 (Le livre d'Elie), los ejemplos más importantes. Ahí hay siempre el

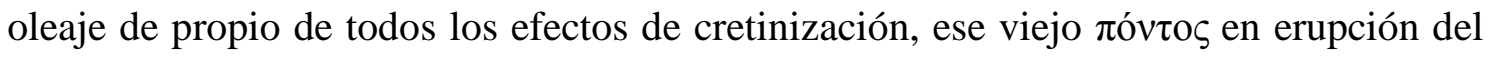
que quiere hacerse hermano el pobre Ducasse en un momento del primer canto ( $c f$. Ducasse, 1973: 31-38); ahí se puede siempre ir o volver, para hacer por primera vez o de nuevo, la prueba («la passion de l'épreuve», Ronell/Nietzsche): la apertura del ojo al «texto oceánico», al «océano primordial» ( $c f$. Ducasse, Sollers, 1964: 152; Blanchot, 1963: 102), al «inmenso azul» y sus «olas de cristal» (cf. Ducasse, 1973: 31). Probablemente, si asumiéramos una cierta generalización tan usada por el propio Derrida (un «en général» es uno de sus tics filosóficos más reconocibles) se trate, más allá de los privilegios que consideramos que ostentan las acotaciones mencionadas, de su efecto de largo alcance, el más persistente, también el más ambiguo. No se trata por tanto simplemente de pensar/escribir la filosofía en efecto, eslogan y punta envenenada

kantismo es irreductiblemente pop; y escribir entonces una «Pop-Kantian Philosophy» enmarcada dentro de los dominos de los actuales Animal Studies. 
de lanza de las publicaciones de Galilée -Glas obligaba a ello desde el primer momento-, sino del efecto, de los efectos, de «la filosofía en efecto»; es decir, de lo que la misma, la de Derrida, provoca en algunos, muchos, de sus lectores. La bêtise, no lo olvidemos, es contagiosa: un efecto general de crétinisation / abêtissement no deja de expandirse y de traspasar, como esa peste del medievo que tan hermosamente es retratada por Artaud al comienzo de Le théâtre de la cruauté (cf. Artaud, 2004: 510$521)$, los castillos y las murallas para instalarse y reproducirse en el corazón de todos los soberanos. No pintar la cosa, sino el efecto que produce ${ }^{12}$.

A la pregunta, siempre anacrónica, sin duda poco conveniente, mala simplemente, «qué quiere decir cretinizar/atontar», se puede responder con lo siguiente: cretinizar/atontar «quiere decir» desencadenar un proceso indefinido de sabotaje del orden del «querer-decir», una disolución sistemática e indefinida de las totalizaciones compresoras de todo tematismo exigidas por ciertos lectores. Dicho de otro modo: la pregunta qué-quiere decir cretinizar/atontar viene ya infectada por un proceso de cretinización/atontamiento. Ahora bien, si cretinizar/atontar quisiera decir esto, en la medida que todo cretinización estaría más allá del orden del querer decir, sería pues siempre más pertinente preguntar no tanto por el qué sino por el quién. «De acuerdo», diría quizá ese otro alguien que contestaría a las impertinencias sentenciosas del supuesto Derrida-scholar, «asumamos por un momento que importe poco y que sea poco conveniente saber qué es, qué quiere decir, ser cretinizado; señáleme entonces las condiciones en las que uno queda cretinizado». Pues bien: se cretiniza, queda cretinizado, aquel que busca -sólo, insistamos en ello, algunos lectores por tanto, pero esos algunos son muchos, multitud, están por todos lados, y participan de (ejecutan) una cierta visión de la lectura, de lo que leer quiere-decir ( $c f$. Lisse, 2001)- un orden de querer-decir (Bedeutung) en la lectura, lectura que es por ende comprendida siempre y fundamentalmente como reunión o congregación unificada del sentido (Versammlung, Heidegger; «C'est toujours le rassemblement [Versammlung] que privilégie Heidegger»; Derrida, 2003: 57; $c f$. Vidarte, 2006: 15-68) -lectura querría decir pues: búsqueda de un querer-decir, arrejuntamiento, del decir en el querer/poder-; ésa sería la condición, y, como se recordará, esto, desde bien pronto, no fue simplemente un tema en Derrida-Bedeutung, La voix et le phénomène, Husserl; luego, de otro modo y desde la herencia de la poética aristotélica, Heidegger-, sino una operación guerrillera emprendida contra $S A-\ll$ Savoir, saveur, goût d'Absolu»-, que tiene su lugar por antonomasia, claudicación de todo tematismo-compresor, en Glas. En definitiva: la

\footnotetext{
${ }^{12}$ Carta de Mallarmé a Cazalis de finales de octubre de 1864: «J'invente une langue qui doit jaillir d'un poétique très nouvelle, que je pourrais définir dans ce deux mots: peindre, non la chose mais l'effet qu'elle produit». Esta cita es parcialmente recogida por Derrida en «La double session» (Derrida, 1972a: 289).
} 
pregunta «qué quiere-decir cretinizar» sólo podría ser realizada o bien por un cretino o bien por alguien que quiere a todas luces llegar a serlo.

En cualquier caso, creemos que pasar por esta situación, la del lector cretinizado -véase la portada de la edición americana de Stupidity ( $c f$. Ronell, 2003): una anciana desdoblada de cabello blanco y largo sobre traje negro pasándolo decididamente mal, mano derecha sobre la frente, ante un gran libro abierto por su final; el título, un gran Stupidity, preside la escena-, situación en la que cada lector singular puede llegar a encontrarse ante la lectura del texto de Derrida, acaba siendo la Stimmung pertinente, necesaria, una especie de purgación saludable, para acceder a este dinamismo indefinido, a este genetismo sin tregua, que es singularmente propio, característico, en los escritos de Derrida -muy particularmente en los años señalados-. Esto no quiere decir que haya una Aufhebung, superación redentora, confesión y cura, de la cretinización o de la bêtise: hay un desplazamiento desde el estado de cretinización, algo que aprender: que de la bêtise no se sale, y que a mayor afán por hacerse el listo -«The temptation is to wage war on stupidity as if it were a vanquishable object», así empieza el libro de Ronell (Ronell, 2003: 3) justo antes de relacionar la guerra contra la bêtise con la guerra contra el narcotráfico emprendida por los Estados Unidos (pero toda cretinización es narcótica: efecto de algún pez torpedo; «stupidity is an opiate» [Ronell, 2003: 57])- más posibilidad hay de hacer una tontería: ésa es la ley de la bêtise. Esto último, en relación precisamente con el $S A$, podría enunciarse también del siguiente modo: a más inteligencia lectora, a más conocimiento (de la obra de Derrida), a más acumulación sintomática de sus motivos y motivaciones, a más dominio de sus variaciones, a, en fin, mayor nivel de «competencia académica», mayor nivel de cretinismo, de estupor, de afasia, de impoder-impoder, que no impotencia, en el que llega, vamos a verlo algo más adelante, la palabra soplada (Artaud; robo), el soplo de vida-. En cierto modo, el mismo, el efecto de cretinización, podría sostenerse también desde la lectura del texto aristotélico en Marges de la philosophie, 1971-1972: puesto que no hay «nombres propios» propiamente hablando, puesto que no hay punto de fuga que trazar, estamos fuera del lenguaje, fuera de lo humano: del lado del animal o de la planta. De este modo, se podría pues decir exagerando sólo un poco, que no hay nadie más cretino, más tonto, más animalizado, dentro de los dominios humanistas del Homo academicus, que el más competente «Derrida-scholar»: o al menos, éste compartiría la pole-position con el mejor de los «Joyce-scholar». Tampoco, en el fondo, puede haber competencia derridiana ( $c f$. Derrida, 1987b: 98).

Ahora bien: ante todo no es que éste, Derrida, busque cretinizar -«ce serait trop ridicule» (Derrida, 1992: 123)-, sino que la cretinización se produce, se da, avanza ya, amenaza con inmovilizar a ciertos lectores, ciertas maneras de leer (porque por 
supuesto, insistimos: la cuestión «qué es, qué quiere decir, leer» no deja de recorrer todo esto; no menos que el hecho de que Derrida lee, ha comenzado por leer, de otra manera). Es decir: que, sobre todo sin quererlo, Derrida habría hecho lo imposible para que, precisamente, los lectores de filosofía sean hoy, después de su muerte, un poco más cretinos, más tontos; que ésta ha sido la manera extremadamente pudorosa -Verhaltenheit ( $c f$. Derrida, 2000: 37)- que ha tenido de hacerlos sentir más vivos; la forma, extremadamente original-Ursprung-que éste ha tenido de hacerse un lugar en la historia de la filosofía occidental; y que lo habrá logrado escribiendo como un salvaje, como un verdadero animal, mientras aspiraba «al mismo tiempo -ó $\mu \alpha$ : la clavija»- a una belleza -recordemos las páginas dedicadas a lo bello y a la intensificación (Beförderung) de la vida desde la lectura de la tercera crítica de Kant ( $c f$. Derrida, 1978b: 117) - cruda y absoluta. Así pues, volverse cretino, tonto o bobo, devenir-cretino, tonto o bobo, cretinizarse poco a poco, reconocer la afección de un cierto cretinismo galopante en el corazón de nuestra imaginación -Einbildungskraft; aporías genéticas del kantismo-, sentir ahí, en el quiasmo abismado entre lo estético y lo lógico, una falta, una carencia para concluir, ver llegar el monstruo o la piedra, poco importa en este sentido, y decir, final y ejemplarmente, como el lector deseado por los Chants de Maldoror: «sí, que no os quepa la menor duda: "il [Derrida] m’a beaucoup crétinisé"». He aquí, creemos, la experiencia, si esta palabra sigue siendo válida, fundamental: la oportunidad misma del pensamiento para abrirse, en otro gran mediodía, desde una dinamicidad indefinida, a su otro más otro.

Ahora bien: si Derrida cretiniza, y lo hace más que nunca en los seventies, es por la búsqueda y reproducción cuasi-performativa de una complicación -amorosa o vital: que dice y hace el amor, y la vida, desde el origen («complication originaire de l'origine», «contamination initiale du simple»; $c f$. Derrida, 1990b: VI-VI), estando abierta siempre, mediante un afirmación sin condiciones, al à venir-. Podría muy bien considerarse que esta complicación, esta irreductible «dificultad de lectura», este «riesgo», que Sollers destaca, adelantémoslo ya, de los Chants, a la vez que señala cómo es precisamente el lector ese personaje central de los mismos Chants (Sollers, 1968: 140, 148) -siempre más allá de un punto simple de rotación, de toda genealogía, de toda seguridad del subjetile, que siempre nos puede traicionar ( $c f$. Derrida, 1986: 55108); siempre más allá de una última destinación, de toda teleología; nudo, entrelazamiento, desplazamiento, son otras palabras a las que Derrida acude numerosas veces-, a partir, si nos concentrásemos en el núcleo conceptual más duro de la tradición filosófica que Derrida lee, de una serie de lecturas de Husserl y de Hegel -en torno a la génesis de lo sensible, a la contaminación original o al superávit del « $\lambda \lambda \eta ́ \rho \omega \mu \alpha »($ Glas), al adelantamiento de la verdad bajo la forma del prólogo-, es, como anunciábamos, la continuación, via philosophice, de una de las empresas más relevantes de la historia de 
la literatura contemporánea: la misma la emprendió ejemplarmente hace un siglo y medio, con recursos bien diferentes, Isidoro Lucien Ducasse, Conde de Lautréamont, con la publicación de los Chants de Maldoror (1869); de él eran esas palabras que citábamos al comienzo: «Il m’a beaucoup crétinisé». Es en el último párrafo del último canto donde encontramos su declaración:

Je veux au moins que le lecteur en deuil puisse se dire: 'Il faut lui rendre justice. Il m'a beaucoup crétinisé. Que n'aurait-il pas fait, s'il eût pu vivre davantage! C'est le meilleur professeur d'hypnotisme que je connaisse'. On gravera ces quelques mots touchants sur le marbre de ma tombe, et mes mânes seront satisfaits! (Ducasse, 1973: 243).

¿Por qué Lautréamont? Quizá Lautréamont no debía faltar a la fiesta que supone un volumen en castellano sobre Derrida y la literatura. «Lautréamont», Conde Drácula, vampiro ( $c f$. Olivier, 1981: 129 y ss.), sanguijuela o gran piojo, de la poesía francesa de finales del XIX descubierto por los surrealistas ${ }^{13}$, $o$ «Ducasse», joven poeta montevideano que desarticula la sintaxis francesa mediante el injerto, aquí y allá, de hispanismos; «Ducasse», como dirá Ph. Sollers que debía siempre ser nombrado, y, sin embargo, como insistirá Artaud en la citada carta que no quería ser nombrado, $o$ «Lautréamont», con su bestiario, sus sapos y sus grullas, sus cangrejos y sus pulpos de mirada de seda con sus tenazas y ventosas, todos esos animalitos que van brotando de las tinieblas o que emergen húmedos de los charcos, fue estudiado por Derrida con detenimiento y precaución. El nombre desdoblado, el desfallecimiento de la propiedad, la biografía imposible, etc.: son algunos greatest hits de Derrida. Y en 1971, en medio de una metamorfosis estilística que le va a llevar, insistimos, a Glas y las cartas de los «Envois», le dedicó un seminario, bastante enigmático, de siete sesiones a algunos aspectos de su obra (Johns Hopkins, Paris). Allí, en la primera página de la primera sesión, anunciando precisamente que se trataba de hacer la experiencia, de estar a la altura, de un «desafío textual», es decir, de todo aquello que pone entre la espada y la pared «la inteligencia de la crítica» (la estupidez y el estupor del lector), afirmaba respecto a los Chants de Maldoror que:

C'est un texte [Chants de Maldoror] devant lequel dirais-je, plus on comprend, plus on se sent bête. C'est cet effet de bêtise qu'il nous faudra analyser. Déjà nous voyons qu'il aura un certain rapport, un double rapport, avec d'une part, le statut ou plutôt le mouvement de la bête, avec la bestialité ou le bestiaire dans les Chants de Maldoror (Bachelard) et avec ce qu'on peut lire au début du dernier paragraphe des Chants, où Maldoror déclare avoir réussi à 'crétiniser' le lecteur (Derrida, 1971: Box 10, Folder 18).

Pregunta pues rápida y anacrónica: ¿No están ya aquí adelantados muchos de los motivos que Derrida va a desarrollar en los años sucesivos? ¿No están aquí conjurados

\footnotetext{
${ }^{13}$ Aunque Sollers, de manera bastante injusta (reductora), considerase en «La science de Lautréamont» que para ellos Lautréamont no era más que un «pretexto de inflación verbal» (cf. Sollers, 1968: 139).
} 
el bestiario y la bêtise (la tontería o la bobada)? Insistimos: «plus on comprend, plus on se sent bête» (es Derrida el que subraya bête [tonto, bobo]); cuanto más se comprende, más tonto, bobo, cretino o bestia se siente (se vuelve) uno. Bien es cierto que de este seminario, y en general de Lautréamont, no han quedado demasiadas huellas explícitas a lo largo de los escritos publicados de Derrida. Desconocemos el motivo. De hecho, una nota a pie en «Hors livre» (1972) -«prefacio» a La Dissémination-, y dos citas que abren la tercera parte de «La mythologie blanche» (1971), parecen ser, que sepamos, las únicas referencias. No obstante, los lugares en los que se encuentran no son insignificantes. Si bien, por tanto, la mera recurrencia no parecería legitimar la traslación, herencia y asunción de este efecto, por un lado: (a) la importancia de estas citas, el lugar y el momento en el que las mismas se encuentran, es vital: es en la nota de «Hors livre» donde encontramos la frase de Lautréamont «Il m'a beaucoup crétinisé» -éstos son los restos que han quedado del seminario de 1971-. Pero la encontramos en una especie de pedrera o cantera: un efecto de castración sin duda. El escenario exactamente es el siguiente: Derrida cita a Lautréamont a propósito de aquello que se problematiza, se complica, desde el principio: la cuestión del prólogo y del prologar, es decir, las cuestiones pendientes de Hegel: el adelantamiento totalizador de la verdad -ya dada como germen, es decir, ya dada en el germen-antes del movimiento de su propia exposición. En concreto, lo que le interesa es el juego del «prefacio híbrido» o del «prefacio renegado» de los Chants de Maldoror: su extraña declaración inicial, su performance. Pero éstas no son las únicas citas. Encontramos otras en «La mythologie blanche»: las mismas son extraídas a propósito de algunas consideraciones de Lautréamont sobre el ejército de metáforas de sus cantos. La palabra que Lautréamont utiliza, en los cantos 4 y 5 , es «simpatía»-«je réserve une bonne part au sympathique emploi de la métaphore»; «se prêter à ce genre de combinaisons sympathiquement curieuses» (Ducasse, 1973: 182, 214; bastardillas nuestras)-, una palabra importante en el léxico que Derrida utiliza cuando se refiere a los animales -simpatía ( $\sigma v \mu \pi \alpha \dot{\theta} \theta \varepsilon \imath \alpha)$, empatía, patético ( $\pi \alpha \theta \eta \tau \iota \kappa o ́ \varsigma)$, empático (toda la cuestión de la Einfühlung), etc.-. No obstante, lo más interesante es la cita que Derrida recoge, en una nota al pie pocas páginas más adelante, de la obra de G. Bachelard Lautréamont (1939): «La longue méditation de l'œuvre de Lautréamont n'a été entreprise par nous qu'en vue de une Psychanalyse de la vie» (cf., Bachelard, 1995: 155; Derrida, 1972b: 316; Blanchot, 1963: 51-188). Derrida parece acceder a Lautréamont por motivos similares, compartidos, a los de Bachelard: un psicoanálisis, una psicografía diríamos, de la vida,

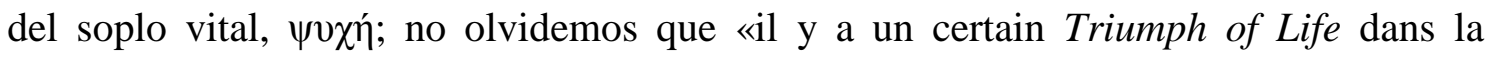
bêtise» ( $c f$. Derrida, 2008b: 249; y que, como es sabido, en «Survivre», Derrida comenta el poema de Shelley The Triumph of Life en el horizonte de L'Arrêt de mort de M. Blanchot). Por otro lado: (b) el tema de la bêtise, que se destaca en la cita recogida 
(«cet effet de bêtise»), apareciendo en algunos textos de finales de los setenta -como Donner le temps. La fausse monnaie (extraído de un seminario de 1975: cf. Derrida, 1991: 49, 208), y como «Une idée de Flaubert: "la lettre de Platon"» (una extraña conferencia de 1980; cf. Derrida, 1987a: 305-326)-, será desarrollado en el primer volumen de su último seminario La bête et le souverain (2001-2002), su «pequeño tratado» sobre la tontería, bêtise. Aquí, las cuestiones referidas al concluir -no tanto cerrar y dominar un entramado textual sino leer para, en vistas a, cerrar y dominar un entramado textual; la modestia de la frasecilla «la interpretación no acaba nunca» es aquí el principal problema- y a la bêtise, volverán a recogerse: Derrida vuelve sobre la exigencia de analizar la bêtise -y lo hará, esta vez, en relación a los textos de Deleuze, Flaubert, Ronell ${ }^{14}$, Valéry y Celan; el efecto de castración, al igual que en el seminario de 1971, no tarda en aparecer; no obstante, no hay rastro de Lautréamont-, y, tras todo un año con la bêtise, acaba abandonando -pero no, ante todo no, concluyendo-: «Abandonnons ici ce petit traité de la bêtise, d'une bêtise qui peut-être revient toujours à s'en tenir à quelque opinion opiniâtre sur la vie la mort (Derrida, 2008b: 410)».

He aquí pues algunas de las cuestiones implicadas en este «efecto de cretinización»: ¿ha seguido de alguna manera Derrida, a lo largo su obra, de sus enseñanzas, de sus cursos y de sus entrevistas, el dictum de Lautréamont? ¿Habría podido igualmente firmar aquella advertencia al lector con la que comienzan los Chants, aquella que decía que: «a menos que ponga en su lectura una lógica rigurosa y una tensión de espíritu igual, como mínimo, a su desconfianza, las emanaciones mortales de este libro embeberán su alma como el agua el azúcar [les émanations mortelles de ce livre imbiberont son âme comme l'eau le sucre]» (Ducasse, 1973: 17). ¿Se inscribe la obra de Derrida, a su modo y mediante sus desplazamientos propios, desde la consideración de Lautréamont, en el proyecto de G. Bachelard -un psicoanálisis de la vida; Sollers hablará de los Chants como, primeramente, puesta en marcha de una psicografía (Sollers usa la misma palabra: $c f$. Sollers, 1968: 149)-? Estas preguntas son sin duda excesivas: para nosotros también son preguntas necesarias. No parece del todo descabellado afirmar todas estas cosas, siempre y cuando se precisen algunas cuestiones. Con ello no se trata en absoluto de trazar una estéril analogía a partir de las misiones o de los intereses de un par de nombres propios: se trata de seguir algunas articulaciones genéticas de la obra de Derrida en la medida de lo imposible y privilegiando algunos de sus gestos.

\footnotetext{
${ }^{14}$ Como es sabido, Ronell habla de la stupidity como «cuasi-concepto»: inestable, variable, plástico, móvil: «...it remains to be seen whether stupidity can be viewed as a concept» ( $c f$. Derrida, 2008b: $231 \mathrm{y}$ ss.; Ronell, 2001: 68). Los problemas de traducción (tonto, bobo, estúpido, mentecato, carajote, etc.) son pues siempre múltiples.
} 
Derrida, su escritura, ha provocado por efecto, paradigmáticamente con su lectura de Husserl -desde las aporías de una fenomenología genética a las complicaciones del problema de la significación (vouloir-dire/Bedeutung, enchevêtrement/Verflechtung)-, y, de forma explícita, a partir del citado seminario sobre Lautréamont (1970-71), la confesión de un lector cretinizado -y Blanchot insistió ya en ello en 1949 en su Lautréamont et Sade ( $c f$. Blanchot, 1963: 88)- que, teniendo una serie de particularidades, se refiere, tiene como punto de arranque, un único y obsesivo

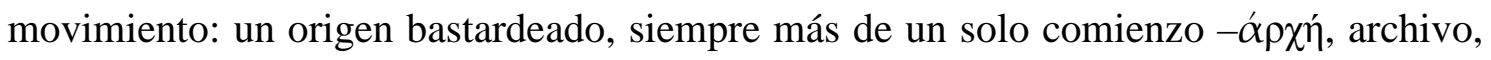
arqueología, etc.: el problema y la violencia de los comienzos-, una práctica escritural híbrida, una teleología castrada, y lo que la misma puede llegar a dar de sí ( $c f$. Derrida, 1990a: 87). Y aunque no será hasta mediados de los setenta cuando la misma se haga patente en lo relativo a una realizatividad explícita -Glas como texto que, estando más allá del saber-significativo (del saber concluyente), está al mismo tiempo atravesado por hordas de animales (bêtes), plantas («écrire veut dire greffer», se leía ya en La dissémination; Derrida, 1972a: 395), flores y piedras; y esta realizatividad querría decir que no sólo se trata de decir cosas, sino de estar a la altura de lo que se dice; es decir, de ser ejemplar: motivo mismo de toda filosofía-, los motivos y estrategias pueden ya reconocerse y reconstruirse desde los primeros escritos, teniendo, como decíamos, su más insistente operación textual en los textos publicados a partir de 1972 y hasta 1980, el momento de la gran zoografía.

Uno estaría tentado a ver en las palabras que citábamos al comienzo de este epígrafe «Ce sentiment de remarquable stupéfaction [...] j'ai fait tous mes efforts pour le produire. En effet, il m'était impossible de faire moins, malgré ma bonne volonté...» (Ducasse, 1973: 229) la firma, a contrapelo, del propio Derrida; pero sólo a condición de cambiar la actividad de los esfuerzos («l'agression inventive» a la que se refiere Bachelard [cf. Bachelard, 1995: 29]) por la pasividad de los efectos. Éstas siguen siendo palabras del malvado Ducasse, para quien la crétinisation/abêtissement es aboutissement. Y la reconocible cretinización general del lector, la castración sistemática y declarada, ese embrutecimiento -abrutir-, de su inteligencia de fines conclusivos, ese no-ver a donde nos conduce el texto ( $c f$. Ducasse, 1973: 229, 260) no es en Derrida, ante todo no es -es importante notarlo e insistir siempre en ello-, un fin en sí mismo -ante todo no hay que buscar, ni inventar, a un cretinizador descendiendo de los cielos con capa al aire, mirada bad boy y camiseta dark side of the moon-; la cretinización/atontamiento no pertenece a los dominios de la teleología del autor -porque, en cierto modo, el gesto de Ducasse volvería al mismo punto (el poder de la metafísica; y se trata, lo vamos a ver enseguida, de otra cosa) por el lado inverso-: es una situación amorosa, una repetición necesaria del instante de la génesis, la actividad de los demiurgos, y del don de lo imprevisible, la que produce pasivamente este estado 
general de cretinización: merma esencial de las facultades teleológicas. Al comienzo de la sesión séptima de este seminario de 1971 -no se trata, insistimos, de realizar un análisis exhaustivo, sino simplemente de marcar algunos lugares importantes-, tiene lugar uno de los grandes momentos del mismo: Derrida compara la situación del lector cretinizado con la del animal sometido, poniendo como ejemplo los experimentos en psicología. Lo hace estableciendo una suerte de analogía entre el lector que se expone a la lectura de los Chants y una rata de laboratorio en un laberinto: cada vez que la comida -el querer-decir del texto (señala Derrida recuperando un término con el que había traducido la Bedeutung que abría las Logische Untersuchungen), es decir, la «solución»- parece cercana, se aleja indefinidamente. A la irritación y la tensión, a la

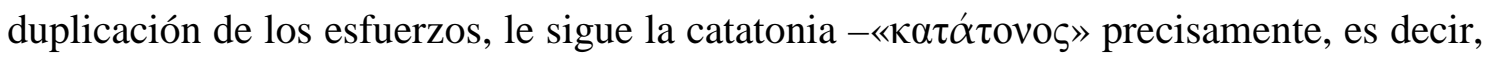
en el sentido del descendimiento, de bajar la cabeza, de la desistencia, de abandonar; del bajar al perder la cabeza (el cap, el rumbo) va un paso, importante, que puede leerse en Derrida-. Es entonces cuando, escribe Derrida, el animal se aburre o se enfada: finalmente, no hay nada que llevarse a la boca: nos han tomado el pelo y faltado el respeto. Es de esto, precisamente, de lo que se trata. No hay que olvidar la importancia que Derrida le dará al problema del aburrimiento años más tarde cuando lea la cuestión del animal en el Heidegger de Die Grundbegriffe der Metaphysik: Welt - EndlichkeitEinsamkeit. Sólo extendiendo esta operación, que Derrida hace confesar a través del otro -eso es precisamente confesarse para éste: confesar al otro en mí: endeudarnos con el otro a través de nosotros mismos; para endeudaros con ellos, no conmigo, escribirá en Circonfession ${ }^{15}$, vemos el alcance de lo que éste está haciendo, o más bien, de lo que produce su hacer. Cualquier hermenéutica, antes o después, se aburre con Derrida, se aburre de él, se abandona a sí misma en una de las esquinas del texto, y muere de inanición, como una rata de laboratorio o como el pobre Asno de Buridán.

Así pues, esta sentencia confesional -sí, «[Derrida] me ha cretinizado mucho»sería pues simplemente el acontecimiento que tendría, una y otra vez, lugar; lo que acabaría sucediendo al tratar de seguir, desde la Crítica, la filosofía como Crítica, y sus instituciones, el trabajo de alguien que ha empeñado su vida filosófica en mostrar a sus lectores que las cosas son (y están) siempre más complicadas de lo que a simple vista parecen. Dicho de otro modo: que no es posible dominar (maîtrise, Herrschaft, Herrswissen-schaft, soberanía del cercado y de la conservación como ciencia general de la lectura) finalmente el texto dado la multiplicidad de motivos que en él se juegan. Porque si bien, después de todo, cualquiera, y particularmente eso que se denomina un profesional o un profesor de filosofía, sabe muy bien, que las cosas son y están siempre

\footnotetext{
${ }^{15}$ Por ejemplo: «...j'arrache la peau, comme toujours, je me démasque et desquame en lisant sagement les autres comme un ange, je me fouille jusqu'au sang, mais en eux, pour ne pas vous faire peur, vous endetter auprès d'eux, non de moi...» (Derrida, J., 2008: p. 20).
} 
más complicadas de lo que parecen, que están complicadas en cuanto que aparecen -cuestión fundamental, fundacional y a la postre castradora ( $a b$ origine y ad extremum), de toda ciencia del aparecer en general, es decir, de toda fenomenología (en el sentido más amplio posible de la expresión; es decir, más allá de toda escuela o proceso de escolarización: ciencia general del aparecer o de los modos de aparición de lo que aparece: embudo total de la fenomenalidad, registro general de la visibilidad), que se quiera seria, es decir, consecuente hasta el fin: no dar nunca nada por sabido, no presuponer para lograr así objetivar-, no cualquiera se esfuerza desmesuradamente, en mostrar que las cosas son así necesariamente reproduciendo dicha complicación por doquier para así, por efecto e inevitablemente, ir poco a poco elevando el desasosiego general, el «sentiment de remarquable stupéfaction», de sus lectores -de ciertos lectores, de ciertas maneras de leer (Asno de Buridán) que habrá que abandonar llegado un cierto momento para poder hacer algo (comer, por ejemplo) con el texto de Derrida-. Pero esto sólo se habrá producido como el efecto, una especie de «mal» menor del que es preciso salir -arriesgarse a ser destruido sabiendo que eso ha de poder evitarse en última instancia, comentará precisamente Derrida ( $c f$. Derrida, 1971: Box 10, Folder 20); ¿No

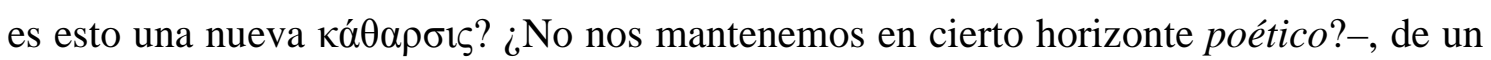
gesto mayor: devolverle a la filosofía una nueva dinamicidad afirmativa.

\section{§ 2. A locas: sobre el impouvoir de pensar.}

Je me suis mis souvent dans cet état d'absurde impossible, pour essayer de faire naître en moi de la pensée [...]. J'ai toujours été frappé de cette obstination de l'esprit à vouloir penser en dimensions et en espaces, et à se fixer sur des états arbitraires des choses pour penser, à penser en segments, en cristalloïdes, et que chaque mode de l'être reste figé sur un commencement, que la pensée ne soit pas en communication instante et ininterrompue avec les choses, mais que cette fixation et ce gel, cette espèce de mise en monuments de l'âme se produise pour ainsi dire AVANT LA PENSÉE. C'est évidemment la bonne condition pour créer. (Antonin Artaud, Le Pèse-nerfs, 1925; bastardillas nuestras).

No se trata sólo de cretinizar, del proceso de aplazamiento sin fin de una ciencia de los fines. Hay también una locura en Derrida: una melancólica (siempre el psicoanálisis: reescrituras de Trauer und Melancholie, 1917) desposesión original no redimible. Ésa ha sido su gran locura (coup de folie / coup de foudre; la locura, los rayos, la pasión; «l'amour fou», justement), una locura genética ( $\gamma \varepsilon \dot{v}$ os), original, genealógica, si se quiere. J.-L. Nancy lo ha dicho muy bien: la locura -«la folie de Derrida»- se debe a su gusto (híper-romántico) por lo imposible -«état d'absurde impossible», escribe Artaud-, a su exceso -«si la folie de Foucault est l'absence 
d'œuvre, celle de Derrida est l'excès de l'œuvre» (Nancy, 2007: 124)-. Pero este exceso no es simple desbordamiento incesante, proliferación inacabable o efecto Big Bang: el exceso, como monstruosidad, es ante todo lo múltiple ab origine (la locura del origen, la locura de los orígenes: la locura aborigen). Esto es lo que funda su peculiar gusto por lo imposible -«exposition à la nécessite de l'impossible» (ibíd.: 129)- y lo que se desprende de la «experiencia», efecto de una cretinización general, sobre el impoder (impouvoir) de pensar propiamente. Derrida no ha dejado de estar interesado por esta «experiencia» post-pop-kantiana (desestabilizaciones del «yo pienso», de la «unidad de apercepción»). Siguiendo lo que hasta ahora hemos tratado de desarrollar, lo podemos decir del siguiente modo: si la denominada «cretinización general» provoca algo -y se debe finalmente a algo- es un cierto impoder: impoder no sólo teleológico, no sólo debido a un no-poder dominar y teledirigir la lectura y las tareas por hacer (unidad de destino: Idea), sino ante todo impouvoir genético, guerrilla indefinida de la filiación múltiple, hundimiento del pensamiento respecto a sí mismo ante la ausencia de un punto de rotación único (archi-écriture), pérdida, desde ahí -«une véritable déperdition», dirá Artaud-, de la ya descrita inteligencia concluyente. De este modo, podría decirse que el efecto de cretinización tiene siempre como resultado (pero al no acabar el efecto, al ser los efectos constantes, el resultado no se da nunca como tal) un cierto decaimiento («ça tombe»; crepúsculo del falo) del pensamiento para consigo mismo: una imposibilidad de pensar, un no tener nada que decir.

Blanchot rescató ya este aspecto en su texto sobre Lautréamont et Sade algunos años antes del seminario de Derrida; y lo definió, desde el estupor, perfectamente: «passivité d'un conscience qui voit tout et ne peut rien» (Blanchot, 1963: 88). «Parálisis significativa» escribirá páginas atrás ( $c f$. Blanchot, 1963: 110) refiriéndose no ya a la experiencia del lector sino a la propia experiencia que atraviesa la escritura de los Chants. Ese «y no puede nada» (la experiencia misma del «ángel de la historia»), es siempre el no poder, el impoder (la remisión al poder, pouvoir/impouvoir, y no a la potencia, puissance/impuissance, es decir, a lo que se tiene o no en acto, y no a lo que se podría o no llegar a tener, es fundamental), del loco, el impoder que trabaja toda genealogía. Quizá sea una buena manera de contextualizar la conocida frase de Derrida: «la folie, une certaine "folie", doit guetter chaque pas, et au fond veiller sur la pensé» (Derrida, 1992: 335). Forcener la filosofía («je ne sais pas si j’écris dans un français intelligible», Derrida, 1986: 59), forzarla a su enloquecimiento (forsené; «hors de sens»; Wahnsinnige, etc.), sacarla de sus casillas, y sacar así también, por ende, al lector. «De ce impouvoir il faut tenir compte», se lee igualmente en Éperons (Derrida, 1978a: 107) en torno a la imposibilidad de saber qué es lo que Nietzsche quiso-decir cuando escribió en una frase perdida de los póstumos de otoño de 1881 que había olvidado su paraguas -Derrida, pero ésta es otra cuestión, reescribe este impouvoir sobre el poder de la «Wille 
zur Macht»; no entramos en ello a pesar de que, en este sentido específico, esto sea un desafío para la hermenéutica a la que venimos de referirnos, es decir, para la consideración de la lectura como Bedeutung/Versammlung-. No obstante, respecto a este carácter general del impoder y de la locura de la filosofía, uno de los momentos más interesantes lo encontramos no ya en los setenta sino algunos años después, en una entrevista con Anne Berger de 1983: «Dialangues», recogida en el volumen de 1992 Points de suspension. Entretiens. Se pregunta Derrida aquí: «Néanmoins, d'où vient le goût sérieux pour la philosophie?». En medio de su argumentación, afirma: «Le philosophe est quelqu'un dont le désir et l'ambition sont absolument fous» (Derrida, 1992: 149) ${ }^{16}$. Y algo más adelante puede leerse:

Il y a une aventure du pouvoir et de l'impouvoir, un jeu de l'impuissance et de la puissance, une taille du désir, qui me paraît, chez les philosophes, beaucoup plus impressionnante qu'ailleurs. Pour moi la philosophie, si j'y ai goût, c'est à cause de cette démesure; c'est hors de proportion avec les autres types de discours, et parfois même avec toutes les règles de l'art (idem).

Ahora bien, al margen de estas correlaciones, lo interesante es que en una entrevista que se recoge algo más adelante en el mismo volumen («Passages - du traumatisme à la promesse», de mayo de 1990) la entrevistadora, Elisabeth Weber, recoge igualmente unas frases sobre la relación de la deconstrucción con el poder, rescatando a su vez otra entrevista de 1989 publicada en The Writing Instructor:

De ce point de vue, la déconstruction n'est ni un outil ni un procédé technique pour maîtriser des textes ou une situation ou quoi que ce soit, elle est au contraire la mémoire d'une certaine absence de pouvoir. Et même les gestes déconstructifs qui paraissent être les plus violents sont [...] une façon de rappeler et de me rappeler à moi-même les limites du pouvoir et de la maîtrise... En cela, il y a un pouvoir (Derrida, 1992: 399).

Tras recordarle sus palabras, la pregunta de Elisabeth Weber es especialmente pertinente: «Quel est le rapport entre, comme vous dites, les monstres de votre écriture et la mémoire de cette absence de pouvoir?». Porque claro: si Derrida fuera monstruoso escribiendo, y si con ello heredase una de las cuestiones más propias de la historia del surrealismo (la generación de monstruos, la apertura de lo monstruoso: la bienvenida dada por el pensamiento a la monstruosidad, su ejercicio) ¿revelaría eso un poder o un impoder? Respuesta de Derrida: «S'il y avait là des monstres, le fait que cette écriture soit en proie à des monstres ou à ses propres monstres marquerait du même coup l'impouvoir» (ídem). Ser presa de los monstruos, de los propios, los de la autobiografía, cuando se escribe, y no tanto de las musas, es la manifestación por antonomasia del

16 «Ces philosophes d'un type nouveau accepteront la contradiction, l'opposition ou la coexistence de valeurs incompatibles. Ils ne chercheront ni à la dissimuler, ni à l'oublier, ni à la surmonter. Et c'est là qui la folie guette mais c'est aussi que son urgence appelle en vérité la pensée» (Derrida, 1994: 52). 
impoder: siempre se está a merced del monstruo. Et pourtant, ésa será siempre la posibilidad misma («en cela, il y a un pouvoir») del pensamiento más allá del pulsión de poder o de dominio soberano -Bemächtigungstrieb (cf. Derrida, 1980: 430-432; Derrida, 2000: 14, 47; ver, saber, poder: Derrida, 2008b: 337-369)-. Derrida, desmarcándose del hecho de que su escritura sea simplemente monstruosa (pero lo es también), dice a continuación: «Plutôt que d'écrire des textes monstrueux, je crois que j'ai, plus d'une fois, utilisé le mot de monstre pour décrire la situation dont je suis en train de parler». Irremediablemente, esto (la «parole soufflée», algo que corta el aliento, que lo roba, y a la vez lo da, lo genera: entre el nacimiento y la disolución de las palabras) recuerda algunas cosas, no simplemente lo que Derrida dice a continuación sobre el à venir como monstruosidad ${ }^{17}$, sino muy particularmente el nombre de A. Artaud que andábamos buscando desde hace rato.

En efecto: al margen de estas cuestiones, que habrían de estudiarse detalladamente más allá de estos ramalazos, aquí, cuando se trata del impouvoir -de la monstruosidad y del hibridismo-, Artaud, como estamos ya viendo desde el ejercicio de un forcener, es protagonista. Con Artaud, ciertamente, no se trata de la bêtise, al menos no preponderantemente, sino de la folie -aunque por lo demás, como se encarga de señalar Ronell, ambas han estado en diversas ocasiones ligadas-. También lo están aquí en lo relativo a los fundamentos anunciados de un surrealismo tout-autre. Artaud escribe prácticamente con los mismos años con los que Lautréamont publica sus Chants, los veintitantos, sus importantes cartas a Rivière ( $c f$. Mèredieu, 2006: 257-260). Quizá hacer el tonto y el loco sea algo propio de la adolescencia del pensamiento; y si esto fuera así, lo que está por ver es que se pueda salir propiamente de ella, o que haya un pensamiento valioso después de la adolescencia (con y después de la «mayoría de edad»). El problema, como señalará igualmente Deleuze en Différence et répétition poco antes de referirse, precisamente, al problema de la bêtise, no es para Artaud orientarse en el pensamiento (Kant: Was heißt: sich im Denken orientieren, 1786), orientación que está perdida de antemano por un efecto general de cretinización, sino «d'arriver tout court à penser quelque chose» (Deleuze, 2005: 191). Querer (pensar) y no poder, saber, dirá Artaud, si se tiene o no el derecho de seguir pensando. No lo olvidamos: el impouvoir es «impouvoir à cristalliser (ibíd., 162)»-ausencia de obra, dirá Foucault: «La folie d'Artaud ne se glisse pas dans les interstices de l'œuvre; elle est précisément l'absence d'œuvre [...] La folie est absolue rupture de l'œuvre; [...]

\footnotetext{
17 «Toute l'histoire a montré que chaque fois qu'un événement s'est produit par exemple dans la philosophie ou dans la poésie, il a pris la forme de l'inacceptable, voire de l'intolérable, de l'incompréhensible, c'est-à-dire d'une certaine monstruosité» (Derrida, 1992: 401). Para un estudio sobre monstruos, desde las herramientas de la fenomenología (derivas del عĩoos), con especial sensibilidad hacia el surrealismo y sus posibilidades, $c f$. Moreno, 2004: 55-75; para otro realizado desde los devenires del romanticismo, $c f$. Duque, 2007: 45-70.
} 
L'œuvre d'Artaud éprouve dans la folie l'absence d'œuvre» (Foucault, 1972: 662)-; y esto es precisamente lo que igualmente llama Blanchot en Le livre à venir en 1959, refiriéndose a la correspondencia con Rivière, «combate» ( $c f$. Blanchot, 1959: 49). Combate del pensamiento consigo mismo, sobre sí mismo -forcener/forsener; «ipso facto cogitans et demens» ( $c f$. Nancy, 2007: 118-139)-, operación límite. Considerando esto, si la correspondencia con Rivière pone de manifiesto algo es precisamente lo que venimos de describir con Lautréamont: que cuanto más cree el lector (Rivière) comprender lo que está pasando, menos comprende -«tout ceci qui est très mal dit risque d'introduire une redoutable équivoque dans votre jugement sur moi», dice ya Artaud en la primera carta, adelantando la propia correspondencia (Artaud, 2004: 70)-: lectura pues emprendida por el crítico, Rivière, al margen de la polemología de los alientos -«il y a dans vos poèmes [...] des maladresses et surtout des étrangetés déconcertantes» (ibíd.: 71)-, incapaz -«avec un peu de patience [...] vous arriverez à écrire des poèmes parfaitement cohérentes et harmonieux» (ídem); al menos Rivière le propuso a Artaud publicar las cartas- de escuchar el murmullo de las larvas ( $c f$. Deleuze, 2005: 155; algo más adelante, en lo relativo a esa verdad de la embriología que adelantábamos al comienzo: «la pensé est plutôt de ces mouvements terribles qui ne peuvent être supportés que dans les conditions d'un sujet larvaire [...] le philosophe est le sujet larvaire de son propre système»). Y es que no se trata de que no pensemos todavía (Heidegger, Was heißt Denken?: «wir noch nicht denken»; bastardilla nuestra), sino de si llegamos, si comenzamos (las genealogías híbridas de Margel vía Artaud; $c f$. Margel, 2008), alguna vez, a pensar, a hacerlo propiamente ${ }^{18}$.

El momento en el que este tema, pero esto no es un «tema», aparece por primera vez en los escritos de Derrida es, como señalábamos, «La parole soufflé», en 1965. Allí podemos leer, tras referirse Derrida al ya citado libro de Blanchot y destacar como éste piensa que el mismo, el impoder, es «essentiel à la pensée» (Blanchot, 1959: 48):

L' “impouvoir", dont le thème apparaît dans les lettres à J. Rivière, n'est pas, on le sait, la simple impuissance, la stérilité du 'rien à dire' ou le défaut d'inspiration. Au contraire, il est l'inspiration elle-même: force d'un vide, tourbillon du souffle d'un souffleur qui aspire vers lui et me dérobe cela même qu'il laisse venir à moi et que j'ai cru pouvoir dire en mon nom. La générosité de l'inspiration, l'irruption positive d'une parole dont je ne sais pas d'où elle vient, dont je sais, si je suis Antonin Artaud, que je ne sais pas d'où elle vient et qui la parle, cette fécondité de l'autre souffle est l'impouvoir: non pas l'absence mais l'irresponsabilité radicale de la parole, l'irresponsabilité comme puissance et origine de la parole. [...] Artaud le répétait sans cesse: l'origine et l'urgence de la parole, ce qui le

18 Parece sintomático que Derrida en un determinado momento, leyendo a Hegel, utilice la palabra impouvoir con una determinación diferente a la que es habitual en sus escritos: «Bien entendu, toute cette logique, cette syntaxe, ces propositions, ces concepts, ces noms, ce langage de Hegel -et, jusqu'à un certain point, celui-ci-, sont engagés dans le système de cet impouvoir, de cette incapacité structurelle de penser sans relève»(Derrida, 1972b: 126). Aquí el impouvoir es un no ser capaz de no pensar sin la dialéctica: cuando el impouvoir es precisamente aquello que desplaza la dialéctica en el ejercicio de su propio movimiento. 
En el origen y urgencia de las palabras, el impoder, que vuelve siempre como la posibilidad misma del desastre, de la catástrofe, no es la ausencia de inspiración, sino la inspiración misma -Deleuze dice algo muy parecido: «Son propre impouvoir [...] qui se confond avec la plus grande puissance» (Deleuze, 2005: 192); en el prefacio de «Freud et la scène de l'écriture», texto que sigue a «La parole soufflée» y que antecede a «Le théâtre de la cruauté et la clôture de la représentation», entre-dos «Artaud», leemos igualmente: «ce pouvoir c'est à dire cet impouvoir qui ouvre, et limite le travail de la force inaugure la traductibilité, rend possible ce qu'on appelle "le langage"» (Derrida, 1967: 316; bastardilla nuestra)-. Treinta años más tarde, Derrida va a usar la misma palabra para referirse a los animales - «et quoi de cette impouvoir, de la vulnérabilité ressentie depuis cette impouvoir»- en L'animal que donc je suis y en el marco de una evaluación y desplazamiento de las distinciones entre lo humano y lo animal desde un cierto poder (cf. Derrida, 1997: 39, 49). Se diría que el pensamiento, en su génesis, allí donde no puede y está a punto de volverse loco, allí donde lo puede todo y nada, es amigo de los animales: que sólo puede ser amigo de los animales un pensamiento original. Pero no vamos a entrar en ello.

Acabamos simplemente destacando cómo, al final de su vida, en el enclave del tener-que-decir-querer-decir, y precisamente en el del impoder, dirá Derrida algo parecido respecto a Artaud y respecto a sí mismo en una entrevista aparecida en 2004: «je me suis trouvé en sympathie [de nuevo el $\pi \alpha \dot{\theta} \theta$ oc] avec cet homme qui disait qu'il n'avait rien à dire, que rien ne lui était dicté en quelque sorte, alors que pourtant l'habitaient la passion, la pulsion de l'écriture» (Derrida, 2004: 34-35; la primera bastardilla es nuestra). Nos podríamos imaginar a Derrida, en su adolescencia argelina, poseído por un mismo sentimiento de desposesión, y diciéndole años más tarde a su profesor M. Foucault, con quien después, en torno a la locura, tendrá las consabidas complicaciones ( $c f$. Derrida, 1967: 51-97), que no tenía nada que decir, que no tenía ideas propias («Écrivez, écrivez, de toute façon ce sera bien», ésa habría sido la respuesta del maestro; $c f$. Ferraris, 2007: 81). Porque, a pesar de todas las alergias que el propio Derrida reconoce en «Artaud, oui...» (cf. Derrida, 2002c: 29; historia de la buena y la mala inspiración, de la consideración del impoder como erosión del pensamiento, del sueño de una vida sin diferencia y de la angustia de desposesión [metafísica de la carne], desde «La parole soufflée»; una especie de metafísico deseo artaudiano de mantener la posición fetal, de evitar el parto: el origen del mundo, el comienzo de la escritura y el legado, como exterioridad y caída, ligado al detritus o a la porquería; «Toute l'écriture est de la cochonnerie», se lee en el Le pèse-nerfs [Artaud, 2004: 165]), 
92 Tropelías. Revista de Teoría de la Literatura y Literatura Comparada, 19 (2013) Federico Rodríguez Gómez

Artaud es, en lo que al acto de escritura se refiere, una especie de doble adolescente de Derrida: hay en éste un amor-odio, un trastorno que no puede dejar de reconocer la fuerza que ella misma repulsa; ésa ha sido la manera que Derrida ha tenido de leer a Artaud, y tal vez también una más de las estrategias que ha inventado para leerse a sí mismo. Quizá se encuentre en la casa de los Derrida el báculo de Saint Patrick: bastón mágico que Artaud «heredó» del pintor surrealista Kristians Tonny y que perdió en Dublin poco antes de que empezase el rosario de sus encierros. En Les Nouvelles Révélations de l'Être se lee que: «cette canne porte au 9e nœud le signe magique de la foudre» (Artaud, 2004: 793; bastardilla nuestra).

Rota, Semana Santa de 2012.

\section{Libros}

ADORNO, TH. W. (1974): «Charakteristik Walter Benjamin», en Kulturkritik und Gesellschaft I. Prismen, en Gesammelte Schriften in zwanzig Bänden. Frankfurt am Main, Suhrkamp Verlag.

ARTAUD, A. (2004): CEuvres. Ed. Éveline Grossman. Paris, Quarto Gallimard.

BACHELARD, G. (1995): Lautréamont. Paris, José Corti (11 a reimpr., nueva edición aumentada).

BLANCHOT, M. (1959): Le livre à venir. Paris, Gallimard. (1963) Lautréamont et Sade. Paris, Minuit.

BENJAMIN, W. (1975): «Der Sürrealismus. Die letzte Momentaufnahme der europäischen Intelligenz», en Gesammelte Schriften, Bd. II/1. Frankfurt am Main, Suhrkamp Verlag.

BONNET, M., ed. (1992): Adhérer au Parti communiste? Septembre - décembre 1926. Paris, Gallimard.

BRANNINGAN, J. (1999): «We have nothing to with Literature. Derrida and Surrealist Writing», en J. Wolfreys, J. Branningan \& R. Robbins, eds., The French Connections of Jacques Derrida. Albany, State University of New York Press.

BRETON, A. (1972): Manifestes du surréalisme. Paris, Jean-Jacques Pauvert (edición completa).

(1973): Entretiens, 1913-1952. Paris, Gallimard.

DERRIDA, J. (1967): L'écriture et la différence. Paris, Éditions du Seuil. (1971): Derrida Papers, Lautréamont, $7^{\mathrm{a}}$ sesión, Box 10, Folder 20, MS-C01. Special Collections and Archives. The UC Irvine Libraries, Irvine, California.

_ (1972a): La dissémination. Paris, Seuil. (1972b): Marges de la philosophie. Paris, Minuit. (1974): Glas. Paris, Galilée. 
Tropelías. Revista de Teoría de la Literatura y Literatura Comparada, 19 (2013) 93

A tontas y a locas. Exigencias de un surrealismo "tout-autre"

(1978): Éperons. Les styles de Nietzsche, Paris, Flammarion (primera versión, «La question du style», en AA. VV., Nietzsche aujourd'hui, Tome I. Paris, Union Générale d'Éditions, 1973).

(1978): «Parergon», en La vérité en peinture. Paris, Flammarion.

(1980): La carte postale de Socrate à Freud et au-delà. Paris, Flammarion.

(1986): «Forcener le subjectile», en P. Thévenin \& J. Derrida, Artaud. Dessins et portraits. Paris, Gallimard.

- (1987a): Psyché. Inventions de l'autre. Paris, Galilée.

- (1987b): «Deux mots pour Joyce», en Ulysse gramophone. Deux mots pour Joyce. Paris, Galilée.

- (1990a): Du droit a la philosophie. Paris, Galilée.

(1990b): Le problème de la genèse dans la philosophie de Husserl. Paris, PUF.

- (1991): Donner le temps. 1. La fausse monnaie. Paris, Galilée.

(1992): Points de suspension. Entretiens. Paris, Galilée.

(1994) Politiques de l'amitié. Paris, Galilée.

(2000): «Foi et savoir. Les deux sources de la 'religion' aux limites de la simple raison», en Foi et Savoir suivi de Le Siècle et le Pardon. Paris, Seuil.

- (2002a): Artaud le Moma. Paris, Galilée.

- (2002b): «Reste - le maître, ou le supplément d'infini», en Lyne Bansat-Boudon

\& John Scheid (éds.) Le disciple et ses maîtres. Pour Charles Malamoud. Paris, Seuil.

- (2002c): «Artaud, oui...», Europe, 873-874 (janvier-février 2002).

- (2003): Psyché. Inventions de l'autre II. Paris, Galilée.

- (2004): «Les voix d'Artaud (la force, la forme, la forge) [entrevista con Évelyne Grossman]», Magazine littéraire, 434.

- (2008a): Circonfession, en Derrida. Paris, Seuil.

_ (2008b): Séminaire La bête et le souverain. Volume I (2001-2002). Paris, Galilée.

DELEUZE, G. (2005): Différence et répétition. Paris, PUF (11ª ed., $2^{\mathrm{a}}$ tirada).

DUCASSE, I. (1973): CEuvres complètes. Les Chants de Maldoror, Lettres. Poésies I et II. Paris, Gallimard.

DUQUE, F. (2007): «La banalización de los monstruos. Lógica del exceso», Daímon Revista de Filosofía, 42.

FERRARIS, M. (2007): Jackie Derrida. Retrato de memoria. Trad. Bruno Mazzoldi. Bogotá, Siglo del Hombre Editores.

FOREST, PH. (1995): Histoire de Tel Quel. 1960-1982. Paris, Seuil.

FOUCAULT, M. (1972): Histoire de la folie à l'âge classique. Paris, Gallimard. 
94 Tropelías. Revista de Teoría de la Literatura y Literatura Comparada, 19 (2013)

Federico Rodríguez Gómez

HEIMONET, J.-M. (1990): Politiques de l'écriture, Bataille / Derrida. Le Sens du sacré dans la pensée française du surréalisme à nos jours. Paris, Éditions JeanMichel Place.

LEDO, R. (2010): O proceso de Artaud (cortometraje).

MÈREDIEU, F. de (2006): C'était Antonin Artaud. Paris, Fayard.

MORENO, C. (2004): «Break-Freak: Fenómeno (Notas para una Geneidética: Eidos y Monstrum»), Daímon Revista de Filosofía, 32.

MARGEL, S. (2008): Antonin Artaud. Les généalogies hybrides. Paris, Galilée.

NIN, A. (1970): Journal 1934-1939. Paris, Stock.

PEETERS, B. (2010): Derrida. Paris, Flammarion.

OLIVIER, J. M. (1981): Lautréamont. Le texte du vampire. Paris, Éditions l'Âge de l'Homme.

RONELL, A. (2001): Stupidity. Urbana \& Chicago, University of Illinois Press.

SOLLERS, PH. (1968): L'écriture et l'expérience des limites. Paris, Éditions du Seuil.

THÉVENIN, P. (2006): Antonin Artaud. Fin de l'ère chrétienne. Paris, Éditions LignesLeo Scheer. 